\title{
Efectos financieros en una cooperativa colombiana por la implementación de estándares internacionales de información financiera para las pyme en su balance de apertura*
}

doi: 10.11144/Javeriana.cc15-38.efcc

\section{Carlos Eduardo Castaño-Rios}

Contador público y magíster en administración, Universidad de Antioquia. Profesor, Departamento de Ciencias Contables, Universidad de Antioquia.

Correo electrónico: eduardo.castano@udea.edu.co

\section{Julián Esteban Zamarra-Londoño}

Contador público, Universidad de Antioquia. Especialista en finanzas y mercado de capitales, Universidad de Medellín. Magíster en administración, Universidad de Antioquia. Profesor, Departamento de Ciencias Contables, Universidad de Antioquia.

Correo electrónico: julian.zamarra@udea.edu.co

\begin{abstract}
Jaime Andrés Correa-García
Contador público y especialista en finanzas, preparación y evaluación de proyectos, Universidad de Antioquia. Magíster en ingeniería administrativa, Universidad Nacional de Colombia. Profesor, Departamento de Ciencias Contables, Universidad de Antioquia.

Correo electrónico: jaime.correa@udea.edu.co
\end{abstract}

\footnotetext{
* Trabajo derivado de la tesis de maestría Impactos financieros por la implementación de NIIF para PYME en una cooperativa de ahorro y crédito. El trabajo de investigación se llevó a cabo durante el año 2012. Se financió con la ayuda del Departamento de Ciencias Contables de la Universidad de Antioquia.
} 
Resumen Dado el proceso de convergencia hacia estándares internacionales de información financiera en Colombia y sus potenciales implicaciones para el empresariado colombiano y en particular para el sector de la economía solidaria, se realizó un estudio de caso, con el objetivo de identificar y analizar los efectos financieros por la implementación de estándares internacionales de información financiera para pyme en una cooperativa colombiana, en particular, en su balance de apertura. Para lograrlo, se simuló la implementación de los estándares internacionales de información para pyme por primera vez para el período 2010 en esa entidad. Los principales resultados arrojaron que el patrimonio y el pasivo se ven altamente impactados de forma negativa, esto debido a la aplicación del estándar referente a los instrumentos financieros. Se concluye que la implementación por primera vez de estos estándares requiere un arduo proceso de planeación para evitar los posibles efectos negativos que podría generar.

Palabras clave NIIF para PYME; implementación por primera vez de NIIF; sector solidario; efectos financieros; cooperativa de ahorro y crédito

\section{Clasificación JEL M41}

\section{Financial Effects on a Colombian} Cooperative due to the Implementation of the International Financial Reporting Standards for SMEs on their Opening Balance

\footnotetext{
Abstract A case study was performed aimed at identifying and analyzing the financial effects of the implementation of international financial reporting standards for SMEs on a Colombian cooperative, particularly, on its opening balance, due to the convergence process towards international financial reporting standards in Colombia and its potential implications for the Colombian business community, particularly for the solidarity economy sector. To achieve this, we simulated the implementation of the
}

international financial reporting standards for SMEs, for the first time, for the 2010 period of this entity. The main results showed that the net worth and the liabilities receive a highly negative impact, due to the application of the standard regarding financial instruments. The conclusion is that the first implementation of these standards requires a difficult planning process to avoid the possible negative effects that it could create.

Keywords IFRS for SMEs; first time implementation of IFRS; solidarity sector; financial effects; savings and credit cooperative

\section{Efeitos financeiros em uma cooperativa colombiana pela implementação de padrões internacionais de informação financeira para as PMEs no seu balanço de abertura}

Resumo Dado o processo de convergência para padrões internacionais de informação financeira na Colômbia e suas potenciais implicações para o empresariado colombiano, e em particular para o setor da economia solidaria, realizou-se um estudo de caso, com o objetivo de identificar e analisar os efeitos financeiros pela implementação de padrões internacionais de informação financeira para PMEs em uma cooperativa colombiana, em particular, no balanço de abertura. Para conseguir, simulou-se a implementação dos padrões internacionais de informação para PME por primeira vez para o período 2010 em tal entidade. Os principais resultados mostraram que o patrimônio e o exigível são altamente impactados de forma negativa, isso devido à aplicação do padrão referente aos instrumentos financeiros. Conclui-se que a implementação por primeira vez desses padrões requer um árduo processo de planejamento para evitar possíveis efeitos negativos que poder-se-ia gerar.

Palavras-chave autor NIIF para PME; implementação por primeira vez de NIIF; setor solidário; efeitos financeiros; cooperativa de poupança e crédito 


\section{Introducción ${ }^{1}$}

El proceso que atraviesa actualmente Colombia para la implementación de estándares internacionales de información financiera cada vez avanza más rápido. Durante diciembre de 2012, se lograron concretar los procesos necesarios a llevar a cabo para la transición hacia los estándares por parte de las entidades que han quedado clasificadas en los grupos 1 y 3 , previamente establecidos por el Consejo Técnico de la Contaduría Pública, CTCP, en el proceso de convergencia hacia estándares internacionales de información financiera en Colombia.

Así, las entidades que han quedado definidas para aplicar NIIF para pyme deben comenzar a prepararse para esta implementación a fin de distinguir sus áreas impactadas, realizar capacitación frente al manejo de este lenguaje financiero y hacer los ajustes en las distintas áreas que puedan verse afectadas. Principalmente, es necesario integrar la información para que los reportes de contabilidad respondan a los requerimientos de los estándares internacionales. En este contexto, aunque las NIIF para PYME solo representen una pequeña parte frente a las full IFRS en cuanto a contenido y extensión de las normas, es

1 A lo largo del texto se utilizarán las expresiones Normas Internacionales de Información Financiera, NIIF o International Financial Reporting Standards, IFRS de forma indistinta, aunque se debe reconocer que cuando se usa la expresión NIIF, esta puede tener algunas diferencias con los IFRS originales debido a los procesos de convergencia que se llevan a cabo en los distintos países. Las NIIF recogen en su composición las denominadas Normas Internacionales de Contabilidad, NIC o International Accounting Standards, IAS, que hasta el año 2000 fueron emitidas por el International Accounting Standards Committee, IASC. necesario entender los cambios y proyectarse para algunas entidades que a futuro podrían pasar al plano de la aplicación de los estándares completos.

En este trabajo, el interés fundamental está en el sector de la economía solidaria, en particular, las cooperativas de ahorro y crédito, que son bastante importantes para Colombia y sobre las cuales se han realizado pocas distinciones en lo corrido del proceso de implementación de los estándares. Adicionalmente, como parte de este trabajo para optar al título de Maestría en Administración, se formuló un proyecto con un estudio de caso, para aplicar y simular los efectos financieros de la implementación de estándares internacionales en una entidad de este sector. El objetivo principal del trabajo es identificar y analizar los efectos financieros de la implementación de estándares internacionales de información financiera para pyme en el balance de apertura de una cooperativa colombiana. Esta entidad es una cooperativa de ahorro y crédito, bastante representativa no solo en el ámbito regional sino nacional, y es clasificada como una de las primeras 50 cooperativas por nivel de activos en Colombia en los años 2012 y $2013^{2}$.

Este trabajo sirve como insumo de planeación para la cooperativa y para todas aquellas entidades de la economía solidaria que por su tamaño serán incluidas entre las obligadas a implementar NIIF para PYME. Es, además, un documento que incorpora las generalidades

\footnotetext{
2 Esta clasificación de entidades es desarrollada por la Confederación de Cooperativas de Colombia, CONFECOOP, anualmente con base en las cifras reportadas por las empresas cooperativas afiliadas.
} 
sobre los potenciales impactos de esta implementación en entidades que tienen las mismas características que la cooperativa y que pueden iniciar un proceso para contrarrestar los efectos esperados.

El artículo se divide en siete grandes apartes sin incluir esta introducción. Inicialmente, se presenta información sobre el sector de la economía solidaria en Colombia y se contextualiza la participación de la cooperativa (el caso analizado). Posteriormente, se analiza cómo ha sido el proceso de convergencia (adopción), en particular para las entidades de economía solidaria en el país. Más adelante, se explica la metodología empleada para obtener los resultados, siguiendo con un conjunto de efectos administrativos asociados al proceso de implementación y luego, un resumen de los principales impactos financieros obtenidos. Este tema se complementa con los ajustes que se generarían en la transición hacia estos estándares internacionales. Por último, se realizan algunas consideraciones finales sobre el tema, que dejan en evidencia que no solo se tienen efectos económicos y financieros, sino también de orden social.

\section{El sector de la economía solidaria en Colombia}

El sector de la economía solidaria comprende básicamente "dos grandes sistemas que funcionan dentro del sector conformado por las organizaciones solidarias, primero, el de las organizaciones de economía solidaria, en el cual se relacionan las organizaciones definidas por la Ley 454 [de 1998]; segundo, corporaciones, fundaciones y asociaciones, las juntas de acción comunal y los grupos de voluntariado" (Cárdenas, 2010, p. 1).

Este tipo de organizaciones son conocidas como las entidades sin ánimo de lucro y por ende, su principal función en la sociedad es el mejoramiento de las condiciones sociales de sus asociados o beneficiarios. En este sentido, se crean un conjunto de principios que rigen su actividad en el país como lo establece el artículo 4 de la Ley 454 de 1998:

1. El ser bueno, su trabajo y mecanismos de cooperación tienen primacía sobre los medios de producción.

2. Espíritu de solidaridad, cooperación, participación y ayuda mutua.

3. Administración democrática, participativa, autogestionaria y emprendedora.

4. Adhesión voluntaria, responsable y abierta.

5. Propiedad asociativa y solidaria sobre los medios de producción.

6. Participación económica de los asociados, en justicia y equidad.

7. Formación e información para sus miembros, de manera permanente, oportuna y progresiva.

8. Autonomía, autodeterminación y autogobierno.

9. Servicio a la comunidad.

10. Integración con otras organizaciones del mismo sector.

11. Promoción de la cultura ecológica.

Adicionalmente, la Ley 454 de 1998 define en su artículo 6 las características de las entida- 
des que hacen parte de la economía solidaria en Colombia de la siguiente forma:

1. Estar organizada como empresa que contemple en su objeto social, el ejercicio de una actividad socioeconómica tendiente a satisfacer necesidades de sus asociados y el desarrollo de obras de servicio comunitario.

2. Tener establecido un vínculo asociativo, fundado en los principios y fines contemplados en la presente ley.

3. Tener incluido en sus estatutos o reglas básicas de funcionamiento la ausencia de ánimo de lucro, movida por la solidaridad, el servicio social o comunitario.

4. Garantizar la igualdad de derechos y obligaciones de sus miembros sin consideración a sus aportes.

5. Establecer en sus estatutos un monto mínimo de aportes sociales no reducibles, debidamente pagados, durante su existencia.

6. Integrarse social y económicamente, sin perjuicio de sus vínculos con otras entidades sin ánimo de lucro que tengan por fin promover el desarrollo integral del ser humano.

Parágrafo 1. En todo caso, las organizaciones de la economía solidaria deberán cumplir con los siguientes principios económicos:

1. Establecer la irrepartibilidad de las reservas sociales y, en caso de liquidación, la del remanente patrimonial.

2. Destinar sus excedentes a la prestación de servicios de carácter social, al crecimiento de sus reservas y fondos, y a reintegrar a sus asociados parte de los mismos en proporción al uso de los servicios o a la participación en el trabajo de la empresa, sin perjuicio de amortizar los aportes y conservarlos en su valor real.

Parágrafo 2. Tienen el carácter de organizaciones solidarias entre otras: cooperativas, los organismos de segundo y tercer grado que agrupen cooperativas u otras formas asociativas y solidarias de propiedad, las instituciones auxiliares de la economía solidaria, las empresas comunitarias, las empresas solidarias de salud, las precooperativas, los fondos de empleados, las asociaciones mutualistas, las empresas de servicios en las formas de administraciones públicas cooperativas, las empresas asociativas de trabajo y todas aquellas formas asociativas solidarias que cumplan con las características mencionadas en el presente capítulo.

Siguiendo lo expresado por la Superintendencia de la Economía Solidaria (2013), en su Balance de 2012, se encontraban en la actualidad bajo su vigilancia 5.437 entidades, de las cuales 185 eran cooperativas de ahorro y crédito. Sumado a esto, este sector reunía en 2012 a 5.305.543 asociados y generaba 80.233 empleos directos.

Las cifras de la Confederación de Cooperativas de Colombia, CONFECOOP, revelan que para el año 2011 las cooperativas representaban el 77\% de las entidades de la economía solidaria, las cuales poseen el $81 \%$ de los activos del sector, el 79\% de los pasivos y el 85\% del patrimonio, como se puede evidenciar en la tabla 1. 
En cuanto a los ingresos generados por el sector cooperativo para la economía solidaria del país, su importancia es mucho mayor, ya que constituye el 93\% del total de ingresos generados por el sector, lo cual tiene una relación directa con la generación de empleo pues tiene este mismo porcentaje de parti- cipación, como se observa en los resultados entregados por CONFECOOP (2012a) y que están en la tabla 2. En cuanto a la cantidad de asociados para las cooperativas, el total de aglomeración es del $83 \%$ y por último, sus excedentes representan el $78 \%$ del total generado por el sector.

\begin{tabular}{lcccccccc}
\hline Naturaleza & $\begin{array}{c}\text { Número } \\
\text { de } \\
\text { entidades }\end{array}$ & (\%) & Activos & (\%) & Pasivos & (\%) & Patrimonio & (\%) \\
\hline Cooperativas & 7.848 & 77 & 24.186 .004 & 81 & 14.330 .748 & 78 & 9.855 .400 & 85 \\
\hline $\begin{array}{l}\text { Fondos de } \\
\text { empleados }\end{array}$ & 2.102 & 20 & 4.921 .663 & 16 & 3.266 .323 & 18 & 1.655 .340 & 14 \\
\hline $\begin{array}{l}\text { Asociaciones } \\
\text { mutuales }\end{array}$ & 292 & 3 & 745.618 & 3 & 655.414 & 4 & 90.204 & 1 \\
\hline Total & 10.242 & 100 & 29.853 .285 & 100 & 18.252 .485 & 100 & 11.600 .944 & 100 \\
\hline
\end{tabular}

Tabla 1. Cifras financieras del sector de la economía solidaria en Colombia para el año 2011 en millones de pesos colombianos - parte 1

Fuente: Confederación de Cooperativas de Colombia, CONFECOOP (2012a)

\begin{tabular}{lcccccccc}
\hline \multicolumn{1}{c}{ Naturaleza } & Ingresos & (\%) & Excedentes & (\%) & Asociados & (\%) & Empleados & (\%) \\
\hline $\begin{array}{l}\text { Cooperativas } \\
\text { Fondos de } \\
\text { empleados }\end{array}$ & 27.991 .478 & 93 & 370.925 & 78 & 5.384 .133 & 83 & 138.549 & 93 \\
\hline $\begin{array}{l}\text { Asociaciones } \\
\text { mutuales }\end{array}$ & 640.412 & 2 & 102.945 & 21 & 922.239 & 14 & 5.532 & 4 \\
\hline \begin{tabular}{l} 
Total \\
\hline
\end{tabular} & 30.556 .316 & 5 & 2.988 & 1 & 213.134 & 3 & 4.890 & 3 \\
\hline
\end{tabular}

Tabla 2. Cifras financieras del sector de la economía solidaria en Colombia para el año 2011 en millones de pesos colombianos - parte 2

Fuente: Confederación de Cooperativas de Colombia, CONFECOOP (2012a)

Lo anterior permite comprender que el sector solidario es bastante importante para el progreso del país, sobre todo si se piensa en ideales de equidad y una mayor solidaridad social. En ese sentido, cualquier regulación (leyes, decretos, resoluciones de superintendencias) que afecte su desempeño de forma negativa puede llevar al traste este tipo de metas.
Entretanto, para el caso particular que se aborda en este trabajo, se tiene que la Cooperativa, "es un organismo cooperativo de primer grado, especializado en ahorro y crédito, sin ánimo de lucro, de responsabilidad limitada, de número de asociados y de capital social variables e ilimitados. Está regida por los principios universales y la doctrina del cooperativismo, la 
ley y sus estatutos" (La Cooperativa, 2012, p. 71). Esta entidad fue creada en 1963 y su domicilio principal está en la ciudad de Medellín, con oficinas en distintos lugares de la ciudad. Adicionalmente, posee oficinas en el municipio de Rionegro y en la ciudad de Bogotá, con lo cual se acerca más a sus asociados actuales y potenciales.

Como parte del logro de su objeto social, la Cooperativa "realiza actividades autorizadas para las cooperativas de ahorro y crédito, mediante la captación de depósitos a la vista y a término, por medio de la expedición de Certificados de Depósitos de Ahorro a Término (CDAT) y recursos de ahorro contractual, para celebrar operaciones activas de crédito y convenios dentro de las disposiciones legales vigentes, así como la prestación de otros servicios que generan ingresos adicionales para la Cooperativa" (La Cooperativa, 2012, p. 71). $\mathrm{Su}$ principal objetivo es de orden social, con respecto a la consecución del bienestar de los profesionales que participan como asociados, lo que produce un impacto positivo para el sector económico en el cual se desempeñan.

Por su parte, la estructura interna de entidad cuenta con un aproximado de $61 \mathrm{em}$ pleados tal como lo plantea su gerente en el Informe de gestión al 31 de diciembre de 2011, donde expresa "a diciembre 31 de 2011 la Cooperativa tenía un total de 61 empleados y a diciembre de 2010, 60 empleados, incluyendo a los aprendices" (La Cooperativa, 2012, p. 71), con lo cual ayuda a generar empleos estables y formales para la economía del país.

La Cooperativa se encuentra inmersa en el sector solidario de la economía colombiana; la entidad aparece en el informe de CONFECOOP entre las 50 cooperativas más grandes del país por nivel de activos. Esta situación es bastante favorable, aunque el sector económico del cual provienen sus asociados ha afrontado dificultades financieras en los últimos años, lo que ha afectado directamente el crecimiento de la Cooperativa y la participación de quienes la conforman.

En Antioquia, la Cooperativa ha estado entre las 20 primeras por total de activos, para los años 2010 y 2011 (Confecoop, 2012a). Si solo se observan las cooperativas de ahorro y crédito en la región, ha logrado estar entre los primeros cinco lugares durante el período analizado, lo cual demuestra la importante participación de esta cooperativa para el país y también como parte del desarrollo regional.

Así mismo, la naturaleza solidaria de la Cooperativa hace que en su dimensión financiera tenga algunas particularidades propias de su objeto social, como la oferta de tasas de interés de captación y colocación en mejores condiciones que las comunes del sector financiero, con lo cual los rendimientos del ahorro serán superiores y los costos del endeudamiento serán menores, lo que promueve una alternativa financiera a sus asociados. Sumado a ello, se promueve el bienestar de sus asociados mediante diversos convenios con otras entidades y la formación especializada de los mismos para que incrementen la calidad de sus servicios, con un impacto importante para el sector en el cual se desempeñan sus asociados. Otros beneficios del interés solidario de la cooperativa se relacionan con el no cobro de cuotas de manejo, se asume el gravamen a los movimientos 
financieros en las operaciones de los asociados, se realizan eventos de integración con las familias, se prestan auxilios económicos por invalidez parcial o total, enfermedad, calamidades, se cubren algunos seguros de forma gratuita como el seguro funerario y el de incapacidad para mayores de 70 años, entre otros.
Los resultados financieros obtenidos por la Cooperativa en los últimos años han sido más que satisfactorios y los excedentes generados se retribuyen a sus asociados como beneficios y mayores posibilidades de bienestar para ellos y sus familias. Los excedentes generados en el período 2008 a 2010 se pueden observar en el gráfico 1.

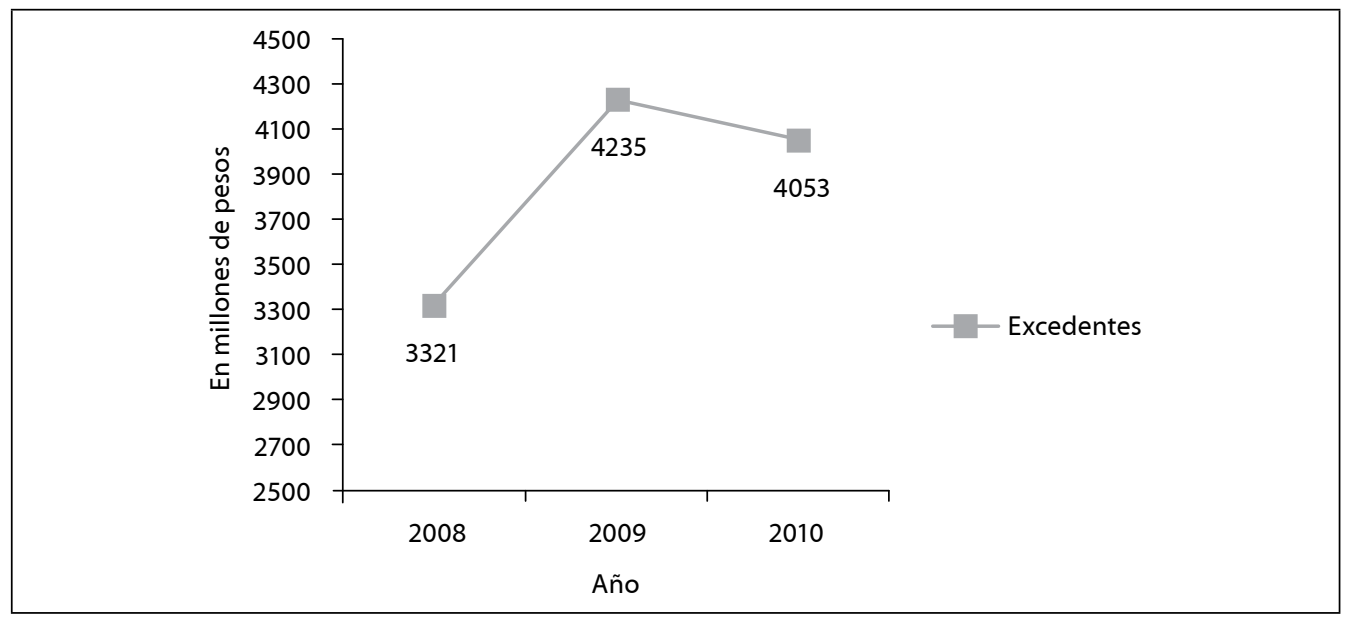

Gráfico 1. Evolución de los excedentes de la cooperativa estudiada Fuente: elaboración propia, a partir de información financiera de la cooperativa

\section{Algunos casos sobre implementación de IFRS en el mundo}

En el ámbito internacional, ya se han realizado diversos procesos de implementación de IFRS que han sido objeto de estudio por parte de algunos autores como se presenta a continuación.

Susana Callao-Gastón, Cristina FerrerGarcía, José Ignacio Jarne-Jarne y José Antonio Laínez-Gadea (2010) realizaron un estudio sobre la implementación de los IFRS en el Reino Unido y en España, y concluyeron que las em- presas españolas presentaron bajos efectos en las cifras contables después de la aplicación de los IFRS, debido principalmente al uso de las excepciones permitidas en la IFRS 1 sobre la adopción por primera vez de estándares internacionales de información financiera. Además, determinaron que la aplicación de IFRS afectó negativamente la relevancia de los reportes financieros en el Reino Unido y en España, porque los valores resultantes en los libros de contabilidad bajo IFRS continúan siendo bastante diferentes a los valores de mercado de las distintas compañías. 
Por otro lado, acerca de la aplicación de las NIIF en las pyme venezolanas, Gerardo Zapata y Aymara Hernández-Arias (2010) indicaron que en muchos casos la problemática gira alrededor de la norma tributaria y del cómo evitar sanciones más que en la línea de aspectos financieros o administrativos; lo anterior se evidencia por la estructura administrativa que tienen las pyme venezolanas, las cuales son muy sensibles a los dictámenes de los auditores fiscales y en muchos casos sus resultados negativos ponen en riesgo la continuidad de los negocios. Por esto, la implementación de normas exige una preparación y madurez financiera y de gestión para las cuales no están preparadas muchas pyme. Todo este proceso requiere una adaptación en la cual hay que invertir diversos recursos y muchas organizaciones de su tamaño no están en disposición de atenderlos. Por todo lo anterior, las pyme deben asumir el cambio a partir del diagnóstico, diseño y planeación, implementación y revisión detallada en el marco de la puesta en marcha de las NIIF.

En Chile, Berta Silva-Palavecinos y Claudio Garrido-Suazo (2006) mencionan que no se desconoce el objetivo que tiene la convergencia de las NIIF, puesto que en línea con el objetivo principal de la IASB que busca un conjunto de normas contables de carácter mundial con alta calidad y que puedan ser el insumo para inversionistas de cualquier lugar del mundo para poder tomar adecuadas decisiones; esto puede ser más fácil si hay entonces una simetría en la información. Mientras tanto, en este mismo país, según Verena Yáñez-Andrades, Fernando Pilar-Cortés y Claudio Inostrosa-Gonzáles (2010), este proceso implica para el profesional contable y financiero un desarrollo mucho más profundo de sus competencias y habilidades profesionales principalmente en temas como “determinación de valores justos, la implementación de nuevos modelos financiero-contables de la empresa, la realización de cálculos de valores actuales, la confección de flujos de caja, el cálculo de tasas de costo de capital, el conocimiento de instrumentos y contabilidades de cobertura, entre otros" (p. 160).

Entretanto, Leandro Cañibano-Calvo y Ana Gisbert-Clemente (2007) presentan un panorama español en el cual las grandes empresas que cotizan en bolsa quedaron obligadas a la presentación de información financiera bajo IFRS; además, distinguieron entre empresas no cotizadas y pyme, para las cuales elaboraron un plan contable armonizado, que simplificaron para este último grupo de empresas. Así mismo, se encuentran estudios como el de Raquel Pérez-Estébanez, Elena Urquía-Grande y Clara Inés Muñoz-Colomina (2009) acerca de la relación de éxito que tienen las pyme que se interesan por la implementación de los IFRS en España y las que no, dado que en España no es obligatorio su uso, a diferencia de lo que se espera suceda en Colombia.

En el caso mexicano, Rafael Lima-Fosado (2006) argumenta que las pyme son un importante grupo de empresas que recoge la mayoría de las organizaciones en este país, por lo que desde la academia se han tomado decisiones para profundizar más en las pyme y con ello fortalecer este sector de la economía e influir en instaurar normas contables que vayan acordes con las características que estas tienen. Adicionalmente, el trabajo realizado por la pro- 
fesora Noemí Vásquez-Quevedo (2013) evidencia para México los siguientes resultados:

Al aplicar la IFRS 1 (Adopción por primera vez), las excepciones obligatorias que más aplicaron las empresas fueron las relacionadas con: estimaciones, contabilidad de coberturas y participaciones no controladoras. Por otra parte, las exenciones opcionales que más fueron utilizadas se refieren a: combinaciones de negocios, beneficios a empleados y costo atribuido.

En resumen, los resultados muestran que la adopción de IFRS refleja la homologación que han tenido las normas mexicanas con las internacionales, y generan expectativas para analizar en futuras investigaciones, mayores implicaciones en los indicadores financieros de las empresas mexicanas (p. 106).

En general, Noemí Vásquez-Quevedo, Mariana Andrea Carril-Márquez y María Pascual-García (2013) encontraron para Latinoamérica y el proceso de implementación de NIIF en general que:

Un factor que influye en que un país decida adoptar las NIIF es la existencia de una bolsa de valores nacional. Los usuarios de la información financiera de las empresas que cotizan en bolsa requieren información que pueda ser entendible y comparable, y las NIIF permiten que esto sea posible pues proveen de estándares contables utilizados en todo el mundo.

Por otro lado, los principales retos que han tenido que enfrentar las empresas son los relacionados con la falta de guías técnico-conta- bles, de guías en la primera adopción de NIIF, de personal calificado y de tecnología (p. 90).

Por último, se debe analizar el caso colombiano, para el cual hay diversas opiniones profesionales en los portales de grandes multinacionales de contabilidad y auditoría como Deloitte, KPMG, Ernst \& Young y PricewaterhouseCoopers, las cuales enuncian las bondades de la implementación de los IFRS tanto para empresas cotizadas en bolsa como para las denominadas pyme, enfocando sus principales beneficios en la internacionalización de las empresas colombianas. Así mismo, portales de actualidad contable - como Actualicese.com y Gerencie.com-manifiestan la importancia para el país de la llegada del lenguaje universal y de los pasos operativos para la implementación, como la preparación del personal, la actualización de las tecnologías, las diferencias entre el lenguaje financiero y el manejo tributario. Además, se encuentran trabajos como el de Fabiola TorresAgudelo y Braulio Adriano Rodríguez-Castro (2008) que evidencia más consecuencias desde el punto de vista conceptual y teórico, como el impacto de la nueva información financiera para su uso por parte de los distintos usuarios de la información, sin trascender al análisis de casos o eventos prácticos de aplicación de estándares en alguna temática cercana a las pyme del país.

\section{Las IFRS para pyme, la economía solidaria y el proceso de convergencia en Colombia}

La dinámica de la economía colombiana y la estrategia de generar competitividad internacio- 
nal para atraer mayor inversión extranjera han llevado a reformas en las normas comerciales, tributarias, laborales y contables, a partir del año 2002. En este entorno surgió la Ley 1314 de 2009 como necesidad de uniformidad en la información financiera en todo tipo de organizaciones. A partir de esa Ley se abrió la posibilidad de que el gobierno nacional modificara el Consejo Técnico de la Contaduría Pública (CTCP) y la Junta Central de Contadores (JCC), órganos de la profesión contable en el país.

En un principio, como parte de la estrategia de trabajo, el 5 de diciembre de $2012^{3}$ el CTCP emitió el documento Direccionamiento estratégico, que estableció tres grupos para la aplicación de IFRS. No obstante, después de las revisiones sobre el proceso de convergencia en Colombia hacia los estándares internacionales, los tres grupos quedaron de la siguiente forma:

Grupo 1. Decreto reglamentario 2784 de 2012, modificado por el decreto reglamentario 3024 de 2013, que establece que las siguientes entidades harán parte del grupo que aplica las NIIF plenas:

Artículo 1. Ámbito de aplicación. El presente decreto será aplicable a los preparadores de información financiera que conforman el Grupo 1, así:

3 El proceso de direccionamiento estratégico del CTCP inició con un primer documento el 22 de junio de 2011; posteriormente, se generó una segunda propuesta el 16 de julio de 2012, que incluye la modificación de los grupos de empresas para aplicar las NIIF y para culminar todo el trabajo, se emitió el documento final de direccionamiento estratégico el 5 de diciembre de 2012 (Direccionamiento estratégico, CTCP). a. Emisores de valores: entidades y negocios fiduciarios que tengan valores inscritos en el Registro Nacional de Valores y Emisores, RNVE, en los términos del artículo 1.1.1.1.1. del Decreto 2555 de 2010.

b. Entidades y negocios de interés público.

c. Entidades que no estén en los literales anteriores, que cuenten con una planta de personal mayor a 200 trabajadores o con activos totales superiores a 30.000 salarios mínimos mensuales legales vigentes (SMMLV) y que, adicionalmente, cumplan cualquiera de los siguientes parámetros:

i. Ser subordinada o sucursal de una compañía extranjera que aplique NIIF plenas.

ii. Ser subordinada o matriz de una compañía nacional que deba aplicar NIIF plenas.

iii. Ser matriz, asociada o negocio conjunto de una o más entidades extranjeras que apliquen NIIF plenas.

iv. Realizar importaciones o exportaciones que representen más del $50 \%$ de las compras o de las ventas, respectivamente.

En el caso de entidades cuya actividad comprenda la prestación de servicios, el porcentaje de las importaciones se medirá por los costos y gastos al exterior y el de exportaciones por los ingresos. Cuando importen materiales para el desarrollo de su objeto social, el porcentaje de compras se establecerá sumando los costos y gastos causados en el exterior más el valor de las materias primas importadas. Las adquisiciones y ventas de activos fijos no se incluirán en este cálculo. 
El cálculo del número de trabajadores y de los activos totales, a que alude el presente literal se hará con base en el promedio de doce (12) meses correspondiente al año anterior al período de preparación obligatoria definido en el cronograma establecido en el artículo 3 del Decreto 2784, o al año inmediatamente anterior al período en el cual se determine la obligación de aplicar el Marco Técnico Normativo de que trata este Decreto, en períodos posteriores al período de preparación obligatoria aludido.

El cumplimiento de las condiciones definidas en los literales a), b), y c)i, c)ii, y c)iii, se evaluará con base en la información existente al cierre del año anterior al período de preparación obligatoria definido en el cronograma establecido en el artículo 3 del Decreto 2784 , o al año inmediatamente anterior al período en el cual se determine la obligación de aplicar el Marco Técnico Normativo de que trata este Decreto, en períodos posteriores al período de preparación obligatoria aludido.

Para efectos del cálculo del número de trabajadores de que trata el inciso primero del literal c), se considerarán como tales aquellas personas que presten de manera personal y directa servicios a la entidad a cambio de una remuneración, independientemente de la naturaleza jurídica del contrato. Se excluyen de esta consideración las personas que presten servicios de consultoría y asesoría eterna. Parágrafo 1. Para los efectos de este decreto son entidades y negocios de interés público los que, previa autorización de la autoridad estatal competente, captan, manejan o ad- ministran recursos del público, y se clasifican en:

a. Establecimientos bancarios, corporaciones financieras, compañías de financiamiento, cooperativas financieras, organismos cooperativos de grado superior y entidades aseguradoras.

b. Sociedades de capitalización, sociedades comisionistas de bolsa, sociedades administradoras de fondos de pensiones y cesantías privadas, sociedades fiduciarias, bolsas de valores, bolsas de bienes y productos agropecuarios, agroindustriales o de otros 'commodities', y sus miembros, sociedades titularizadoras, cámaras de compensación de bolsas de bienes, y productos agropecuarios, agroindustriales o de otros 'commodities', sociedades administradoras de depósitos centralizados de valores, cámaras de riesgo central de contraparte, sociedades administradoras de inversión, sociedades de intermediación cambiaría y servicios financieros especiales (SICA y $\mathrm{SFE}$ ), los fondos de pensiones voluntarios y obligatorios, los fondos de cesantías, los fondos de inversión colectiva, y las universalidades de que trata la Ley 546 de 1999 y el Decreto 2555 de 2010 y otros que cumplan con esta definición.

Parágrafo 2. Los portafolios de terceros administrados por las sociedades comisionistas de bolsa de valores, los negocios fiduciarios y cualquier otro vehículo de propósito especial, administrados por entidades vigiladas por la Superintendencia Financiera de Colombia, deberán establecer contractualmente si aplican o no el marco técnico nor- 
mativo establecido en el Anexo del Decreto

2784 de 2012.

Grupo 2. Decreto reglamentario 3022 de 2013, por el cual estableció que las entidades que aplicarán la NIIF para PYME serán:

a. Entidades que no cumplan con los requisitos del artículo 1 del Decreto 2784 de 2012 y sus modificaciones o adiciones, ni con los requisitos del capítulo 1 del marco técnico normativo de información financiera anexo al decreto 2706 de 2012.

b. Los portafolios de terceros administrados por las sociedades comisionistas de bolsa de valores, los negocios fiduciarios y cualquier otro vehículo de propósito especial, administrados por entidades vigiladas por la Superintendencia Financiera de Colombia, que no establezcan contractualmente aplicar el marco técnico normativo establecido en el Anexo del Decreto 2784 de 2012 ni sean de interés público.

Cuando sea necesario, el cálculo del número de trabajadores y de los activos totales para establecer la pertenencia al Grupo 2, se hará con base en el promedio de doce (12) meses correspondiente al año anterior al período de preparación obligatoria definido en el cronograma establecido en el artículo 3 de este Decreto, o al año inmediatamente anterior al período en el cual se determine la obligación de aplicar el Marco Técnico Normativo de que trata este Decreto, en períodos posteriores al período de preparación obligatoria aludido.

\begin{abstract}
Para efectos del cálculo de número de trabajadores, se considerarán como tales aquellas personas que presten de manera personal y directa servicios a la entidad a cambio de una remuneración, independientemente de la naturaleza jurídica del contrato.
\end{abstract}

\section{Grupo 3. Decreto reglamentario 2706 de} 2012, modificado por el decreto reglamentario 3019 de 2013, en el cual se establece que aplicarán la NIF para microempresas las siguientes entidades:

\subsection{Aplicarán esta NIF las microempresas} que cumplan la totalidad de los siguientes requisitos:

a. Contar con una planta de personal no superior a diez (10) trabajadores.

b. Poseer activos totales, excluida la vivienda, por valor inferior a quinientos (500) salarios mínimos mensuales legales vigentes (SMMLV).

c. Tener ingresos brutos anuales inferiores a 6.000 SMMLV.

Para efectos del cálculo de número de trabajadores, se consideran como tales aquellas personas que presten de manera personal y directa servicios a la entidad a cambio de una remuneración, independientemente de la naturaleza jurídica del contrato; se excluyen de esta consideración las personas que presten servicios de consultoría y asesoría externa.

El cálculo del número de trabajadores y de los activos totales, a que aluden los literales (a) y (b) anteriores, se hará con base en el promedio de doce (12) meses, correspon- 
diente al año anterior al período de preparación obligatoria definido en el cronograma establecido en el artículo 3, del Decreto 2706, o al año inmediatamente anterior al período en el cual se determine la obligación de aplicar, el Marco Técnico Normativo de que trata este Decreto, en períodos posteriores al período de preparación obligatoria aludido.

Las mismas reglas se aplicarán para la determinación de los ingresos brutos a que alude el literal (c) anterior.

En el caso de microempresas nuevas, estos requisitos se medirán en función de la información existente al momento del inicio de operaciones de la entidad.

De acuerdo con lo establecido en el artículo 2 de la Ley 1314 de 2009, esta norma será aplicable a todas las personas naturales y entidades obligadas a llevar contabilidad que cumplan los parámetros de los anteriores literales, independientemente de si tienen o no ánimo de lucro.

1.3 También deben aplicar el presente marco técnico normativo las personas naturales y entidades formalizadas o en proceso de formalización que cumplan con la totalidad de los requisitos establecidos en el artículo 499 del Estatuto Tributario y las normas que lo modifiquen o adicionen.

Así las cosas, las entidades como la Cooperativa - cooperativas cerradas de tamaño grande, mediano o pequeño- no fueron consideradas de interés público, ya que según el CTCP "el carácter público implica que son organizaciones de tipo abierto, por lo cual no están restringidas a un grupo específico de usuarios, clientes, o afiliados" (CTCP, 2012, p. 17). Esto implica que están en el camino de la aplicación de las NIIF para PYME ${ }^{4}$ como el caso estudiado y también podrían quedar inmersas en el grupo 1 para las cooperativas financieras y grupo 3 para aquellas que son de menor tamaño.

\section{Metodología}

Para el desarrollo de este trabajo, se utilizó un estudio de caso, llevado a cabo en la Cooperativa, cuyas operaciones principales se centran en las actividades de ahorro y crédito con amplios beneficios para sus asociados, como se explicó anteriormente.

De este modo, y siguiendo el proceso de implementación de NIIF en Colombia que adelanta el CTCP y los Ministerios delegados para tal fin, las normas que serán aplicables a la Cooperativa son las correspondientes a las del grupo 2 y para ello el equipo de trabajo ejecutó las siguientes etapas para la obtención de los efectos financieros producto de esta implementación:

1. Conocimiento del sistema de información contable (SIC) de la Cooperativa.

2. Sensibilización y capacitación general sobre el tema de IFRS para el personal involucrado en la implementación de las IFRS.

3. Comparación de las normas colombianas con las NIIF para PYME.

4 No obstante, el Decreto reglamentario 2784 de 2012 y la circular externa 1 de 2013 de la Supersolidaria de Colombia dejan en las entidades la potestad de aplicar NIIF plenas de forma voluntaria siempre y cuando permanezcan al menos tres años en el modelo completo de NIIF. 
4. Desarrollo del manual de políticas contables para la entidad bajo la NIIF para PYME.

5. Diseño de supuestos para la evaluación de los impactos financieros, dado que en la actualidad aún no es necesaria la aplicación de NIIF para la entidad.

6. Simulación de resultados financieros con el modelo de IFRS para PYME en la información financiera de la Cooperativa con la información financiera al 31 de diciembre de 2010.

7. Análisis de los resultados obtenidos y conclusiones del trabajo.

\section{Efectos administrativos en la Cooperativa por la implementación de las NIIF para PYME}

En la Cooperativa se realizó un diagnóstico general de la organización frente a la implementación de las NIIF para PYME, teniendo en cuenta las necesidades que se podían generar para la administración de la Cooperativa. De acuerdo con los resultados obtenidos, se determinó el impacto en las principales áreas de la entidad, como se evidencia en la tabla 3.

\begin{tabular}{|c|c|}
\hline Área & Impactos \\
\hline Alta gerencia & $\begin{array}{l}\text { - Requiere conocimiento de las nuevas prácticas de contabilidad y su incidencia en los reportes financieros. } \\
\text { - Debe requerir informes gerenciales diferentes a la información financiera de estados financieros } \\
\text { básicos para la toma de decisiones internas. }\end{array}$ \\
\hline $\begin{array}{l}\text { Revisoría } \\
\text { fiscal }\end{array}$ & $\begin{array}{l}\text { - Tendrá que implementar nuevas prácticas de auditoría basadas en estándares internacionales para } \\
\text { verificar el cumplimiento de la entidad con la revelación bajo IFRS. }\end{array}$ \\
\hline $\begin{array}{l}\text { Dirección } \\
\text { financiera }\end{array}$ & $\begin{array}{l}\text { - Es el principal responsable de revelación de la información y análisis de la misma para la entrega a la } \\
\text { Alta Gerencia y apoyo en la toma de decisiones. Aquí se impactan directamente los procedimientos } \\
\text { del área de contabilidad y las operaciones con inversiones. } \\
\text { - Apoya la generación de las nuevas políticas de contabilidad. } \\
\text { - Como se incrementa el valor a administrar en las inversiones de Ley (Fondo de liquidez), se debe } \\
\text { replantear este portafolio para que cumpla estos requerimientos. De este modo, es necesario revisar el } \\
\text { conjunto de inversiones actuales frente a los mínimos exigidos por la norma para las inversiones de ley } \\
\text { y así seguir cumpliendo esta regulación. }\end{array}$ \\
\hline $\begin{array}{l}\text { Dirección } \\
\text { administrativa }\end{array}$ & $\begin{array}{l}\text { - Requiere información financiera para la toma de decisiones y necesita conocer cómo se le está presentando. } \\
\text { - El área de sistemas es fundamental en el proceso de cambio y requiere actualización. Además, un } \\
\text { sistema integrado de información bajo los requerimientos IFRS. } \\
\text { - Reorganizar el sistema de costos para que se pueda disponer de información detallada por línea } \\
\text { de crédito y establecer políticas diferenciadas sobre qué productos financieros se deben ofrecer a } \\
\text { los asociados que además, favorezcan el logro de los objetivos de la entidad en equilibrio con sus } \\
\text { resultados financieros. } \\
\text { - Debe requerir informes gerenciales diferentes a la información financiera de estados financieros básicos. }\end{array}$ \\
\hline $\begin{array}{l}\text { Dirección de } \\
\text { mercadeo }\end{array}$ & $\begin{array}{l}\text { Debe conocer el impacto de su función en los resultados financieros, para ello necesita conocer los } \\
\text { cambios en la información financiera. } \\
\text { - Suministra información gerencial de mercado para la toma de decisiones, diferente a la información } \\
\text { financiera. }\end{array}$ \\
\hline
\end{tabular}


La tabla 3 muestra cómo el conocimiento y la implementación de nuevas prácticas, las nuevas responsabilidades y los cambios en general que se presentan en las funciones de los empleados en las diferentes áreas de la organización requieren que la entidad incremente el personal, para que quienes están actualmente en la entidad puedan llevar a cabo y responder a los requerimientos que conlleva la implementación de las NIIF, situación que se da principalmente en el área de la dirección financiera y en particular, en el componente contable. Por otro lado, aunque hay software especializado para abordar el proceso de transición, los tiempos de capacitación, ajustes y demás actividades propias del área contable y financiera pueden llevar nuevamente a requerir apoyo de otras personas para abordar esta compleja tarea.

Otro aspecto que se considera de alto impacto con la implementación de las NIIF para PYME es el relacionado con los sistemas de información; este proceso trae importantes consecuencias en el sistema que la mayoría de las veces implican el cambio del sistema de información. El nuevo sistema de información debe permitir la generación de mayor información de manera oportuna y de mayor nivel de detalle, como lo exigen las revelaciones de las NIIF. En este sentido, se requiere actualizar el software de la organización frente a las necesidades de IFRS como las siguientes:

- El sistema tendrá que soportar al menos durante un período contable, la existencia de tres bases diferentes de reporte de información a saber: actual bajo PCGA, IFRS y tributario.
- Se presentarán mayores diferencias entre la información a reportar a entidades fiscalizadoras como la DIAN, y las requeridas por la Superintendencia de la Economía Solidaria y los usuarios externos.

- El sistema de información debe trabajar de forma mucho más integrada y por ello, el módulo de inversiones debe estar integrado al sistema general de información.

- Se deben poseer modelos internos ${ }^{5}$ para el cálculo del valor razonable de activos y pasivos financieros.

- El sistema debe ser dinámico en su agilidad para permitir los ajustes que exigen las IFRS.

- Los reportes de información financiera se incrementan y con ello, la necesidad de información más detallada.

En general, los impactos organizacionales de este tipo generan importantes cambios en la gestión de la Cooperativa; estas situaciones llevan a una crisis coyuntural que puede ser minimizada siempre y cuando se realice una preparación adecuada frente a estas variaciones.

\section{Estudio de caso: impactos financieros de la implementación de IFRS en una Cooperativa}

La implementación de IFRS es un proceso que debe ser planeado y que no solo implica cam-

\footnotetext{
5 Modelos internos de valoración de activos y pasivos que permitan evaluar permanentemente los resultados que se reflejan en la contabilidad y aspectos como el deterioro de valor.
} 
biar la forma de llevar la contabilidad en las organizaciones, sino que requiere diversos cambios en el día a día de las distintas áreas de la organización. Lo primero que se debe realizar en este tipo de implementaciones es una sensibilización del personal clave de la entidad (incluidos los accionistas, socios y asociados, según el caso), debido a que es relevante que ellos mismos comprendan que toda la organización queda involucrada en el proceso y además, tomarán decisiones sobre una información que se presentará de forma diferente para los períodos contables en los cuales ya se empiece a aplicar la nueva norma de contabilidad.

De este modo, se analizaron las áreas clave de implementación de IFRS en la Cooperativa, bajo el supuesto de aplicación de IFRS para PYME con las posteriores repercusiones en las distintas áreas de la entidad que se veían comprometidas en ese proceso. Autores como Hernán Pablo Casinelli (2012), Néstor Alberto Jiménez-Jaimes (2011), Samuel Alberto Mantilla (2011) y Deloitte (2008) manifiestan la importancia del análisis de la información para la implementación por primera vez de las IFRS y de identificar las principales áreas involucradas. Así mismo, es de anotar que en la adopción por primera vez, se aplican las IFRS que estarían vigentes una vez se presentan los primeros estados financieros comparativos bajo IFRS; para este análisis, las NIIF para PYME vigentes desde 2009.

Adicionalmente, como parte del análisis de la cooperativa, se evidenció que los rubros más significativos de su información financiera son su cartera, las inversiones, los depósitos y los aportes sociales (como se puede observar en las tablas 4 y 5, en la columna de saldos iniciales). Desde este punto de vista, el análisis de lo que sucede en estos elementos es fundamental en los resultados obtenidos.

Sin embargo, para la preparación del estado de situación de apertura, fue necesario realizar algunos supuestos, dada la complejidad de algunos temas para hacer los cambios o la ausencia de información en algunos casos, dejando los siguientes elementos y consideraciones:

1. La entidad no tiene un modelo operando plenamente que permita establecer el costo que se generó para cada crédito otorgado a fin de reconocerlo dentro del modelo como parte activa para calcular la tasa de interés efectiva.

2. Como costo atribuido de la Propiedad, Planta y Equipo (en adelante, PPyE) de las oficinas en Centro, Poblado y Laureles, para el 31 de diciembre de 2010, se utilizó el modelo de costo atribuido que implica la actualización del valor de la PPyE mencionada más las valorizaciones previamente realizadas, menos la depreciación acumulada por un año, correspondiente al período 2010 , ya que el avalúo se realizó en diciembre de 2009.

3. Se aplica de forma anticipada la NIIF 9, norma expedida en 2009 por el IASB, pero que ha venido reemplazando paulatinamente la NIC $39^{6}$. Sumado a ello, para las

6 La NIIF para PYME en su sección 11 expresa que una entidad podrá optar en el tema de instrumentos financieros entre la aplicación de sus secciones 11 y 12 o las disposiciones de la NIC 39. Adicionalmente, se puede interpretar que con el cambio paulatino de la NIC 39 por la NIIF 9 se hará necesario transitar hacia la NIIF 9 por lo cual, para este ejercicio académico se realiza este supuesto, que además le 
entidades cooperativas fue emitida una interpretación con referencia al tratamiento de su patrimonio, este documento es conocido como la interpretación CINIIF $2^{7}$, Aportaciones de socios de entidades cooperativas e instrumentos similares, y en ella se establece que esos aportes a las entidades cooperativas se consideran patrimonio cuando hay una cláusula estatutaria o una norma estatal que prohíba el retiro total o parcial de los aportes de los asociados. En su caso, con las leyes 454 de 1998 y 79 de 1988, la Cooperativa estableció en los estatutos como capital mínimo irreductible un monto de 15.000 SMMLV.

4. La cartera, las cuentas por cobrar, los depósitos a término fijo y las inversiones financieras, cuya medición a costo amortizado bajo NIIF para PYME se obtiene con el método de la tasa de interés efectiva no presentarían una variación en su valor para los años 2010 y 2011 por los siguientes motivos:

a. El valor inicial de la cartera, las cuentas por cobrar, los depósitos a término fijo y las inversiones financieras no tiene separación de los costos de transacción con los respectivos valores nominales que hacen parte de la operación financiera. Además, para las inversiones en mercado de valores mantenidas hasta el vencimiento cuando se puede conocer la diferencia entre el valor nominal y el

puede aportar interesantes elementos a la Cooperativa en torno a la medición y reconocimiento de sus instrumentos financieros.

7 Comité de Interpretación de las Normas Internacionales de Información Financiera, CINIIF. costo de adquisición, se está aplicando la política de reconocimiento de la inversión a valor razonable y por tanto, el flujo de inicio es igual que para el método de la tasa de interés efectiva.

b. Las inversiones financieras en títulos de renta fija y variable en mercado de valores son aproximadamente el $22 \%$ del total de activos y están representadas en inversiones de renta fija en su gran mayoría, además están valoradas a valor presente neto, utilizando la tasa de interés de mercado. Con el modelo de valoración establecido actualmente se reconoce el valor de la inversión y se tiene en cuenta el deterioro o no de valor de la misma. Con esto los flujos de caja futuros esperados son iguales bajo el método de la tasa de interés efectiva que con los datos actuales y por ello, no hay diferencias en esta valoración.

5. Como las inversiones permanentes (aportes) que se poseen en la actualidad son en las entidades Seguros la Equidad y CONFECOOP, esta inversión se mide al costo menos deterioro. A la fecha no se evidenció ningún deterioro en estas inversiones.

6. Las nuevas vidas útiles para equipos de cómputo y comunicaciones (4 años), edificios (50 años) y equipo de oficina (10 años) serán parte de las políticas de contabilidad y son la base para realizar las nuevas depreciaciones.

7. Las obligaciones financieras cambian su nombre por otras obligaciones, dada su naturaleza. Adicionalmente, estas otras obligaciones no poseen un vencimiento claro 
y por ende, se valoran por el valor que aparece en la actualidad. Hoy, la Cooperativa no tiene obligaciones financieras como las tradicionales con entidades del sector financiero o con otras entidades del sector solidario que tengan actividad financiera. Esta situación se presenta porque la Cooperativa posee excedentes de liquidez y por ello, no es necesario recurrir al endeudamiento financiero. No obstante, este rubro figura en su actual balance general, pero corresponde tal como lo indica su informe de gestión a "la reclasificación contable por cheques girados y no cobrados; también a las consignaciones en tránsito y transferencias no identificadas" (La Cooperativa, 2012, p. 91). De entrada, esta situación debe ser revisada por la entidad pues no cumple la normativa vigente, ya que estos conceptos no satisfacen la definición de obligación financiera como lo establece la circular básica contable de la Superintendencia Solidaria de Colombia.

8. Para los deterioros de valor de la cartera, que sean diferentes a las provisiones ya practicadas por la Cooperativa no son necesarios otros criterios a los ya aplicados ${ }^{8}$.

9. No se presenta la información por segmentos, ya que no se cuenta con la información detallada y separada de las diferentes unida-

8 A partir de la emisión del Decreto reglamentario 1851 de 2013 para el sector financiero y en concordancia con la circular 3 de la Supersolidaria, los actuales procedimientos para hallar los deterioros de la cartera hacen que los valores hallados sean superiores a los que se calcularían bajo los procedimientos de la NIIF para PYME; no obstante, esta modificación en la norma para Colombia va en línea con la protección que desea el gobierno para el sistema financiero en la actualidad. des de negocio de la Cooperativa para el año 2010. Aquí es importante destacar que la presentación de información por segmentos no es obligatoria en la NIIF para PYME, pero la distinción de las unidades de negocio de la cooperativa sería bastante útil para los procesos de toma de decisiones de los distintos usuarios de la información.

Con los anteriores supuestos y consideraciones, se realizaron los ajustes respectivos para 2010, como se evidencia en la tabla 4 para los activos y en la tabla 5 para los pasivos y el patrimonio. Allí se puede observar que los principales impactos desde el punto de vista financiero están en el cambio del patrimonio (aportes sociales, con excepción del capital mínimo irreductible) por pasivo (depósitos de largo plazo), debido a que estos aportes no tienen la calidad exigida por los estándares internacionales para ser reconocidos como patrimonio, es decir, la Cooperativa solo puede exigir que se mantenga el capital hasta el mínimo irreductible; el resto puede ser retirado por los asociados en cualquier momento y además, estos aportes no generan una participación proporcional en la entidad y tampoco generan dividendos ya que es una entidad sin ánimo de lucro. Con este resultado, los pasivos se incrementan cerca de un 38\% por esta reclasificación. Por su parte, el patrimonio disminuye dramáticamente alrededor de un 50\% como resultado de la reclasificación de aportes mencionada y el efecto que produce en la implementación por primera vez, la diferencia del valor de la PPyE y llevar los gastos diferidos directamente a resultados de ejercicios anteriores. 
Ante el escenario planteado para este trabajo, también es necesario reconocer que tanto los excedentes futuros como los flujos de caja esperados en la operación de la Cooperativa, se verían reducidos (por el costo de la tasa de interés), dado el efecto de los nuevos pasivos de largo plazo que serían producto de la reclasificación de los aportes, con excepción de que como parte de la planeación se tome la decisión de llegar a un escenario en el cual estos pasivos no generen rendimientos directos a pagar a los asociados siguiendo la lógica actual de los aportes; por lo cual, al reconocer el costo implícito del pasivo se registraría contra un ingreso, neutralizando el efecto total sobre el excedente y sobre los flujos de efectivo, lo cual podría ser una decisión del máximo órgano de la entidad.

Por otro lado, al revisar el tema de los instrumentos financieros - uno de los más importantes para la Cooperativa-, se optó por tomar las definiciones contenidas en la NIC $39^{9}$, dado que la IFRS para PYME lo permite. De este modo, los instrumentos financieros se clasifican en dos grandes grupos: a costo amortizado y a valor razonable. Sin embargo, al utilizar la metodología planteada para el modelo del costo amortizado con el método de la tasa de interés efectiva, no fue posible evidenciar grandes diferencias entre lo actualmente aplicado en la Cooperativa y lo que serían los resultados del modelo, debido a que una parte importante de los créditos no tenía un costo identificable al momento de su desembolso que generara una diferencia entre la tasa de interés efectiva y la

9 Se toman algunos elementos de la NIC 39, ya que aún no ha sido reemplazada en su totalidad por la NIIF 9 en el tratamiento contable de los instrumentos financieros. tasa de interés pactada en el crédito, como se planteó en los supuestos y consideraciones anteriormente mencionadas.

En cuanto a la propiedad, planta y equipo (PPyE), se obtuvieron diversos impactos en la implementación, producto de la reclasificación de un anticipo para PPyE, la revalorización de los edificios que poseían avalúos y los respectivos ajustes con las nuevas vidas útiles definidas para los distintos conceptos a saber:

\section{Edificios}

50 años

Muebles y enseres 10 años

Equipo de cómputo y comunicaciones 4 años

Estas vidas útiles surgen de un análisis realizado junto con la administración de la Cooperativa, que consideró que la actual vida útil de 20 años de los edificios realmente era baja para el tiempo que puede estar vigente un edificio (unos 100 años desde su construcción, incluyendo el mantenimiento y las reparaciones que se hacen sobre ellos de forma habitual), por lo cual se incrementó esta estimación hasta 50 años. En cuanto a los muebles y enseres, una vida útil de diez (10) años tiene mayor consistencia, como se viene aplicando como política contable, pero para los equipos de cómputo y comunicaciones se encontró que cinco (5) años era bastante, debido a la actual obsolescencia de todos estos activos tecnológicos, aunque tampoco era viable disminuir radicalmente su vida útil puesto que había evidencia de activos de este tipo que eran utilizados por períodos cercanos a los diez (10) años, lo que permitió concluir que una vida útil de cuatro (4) años tenía mayor razonabilidad. 
De este modo, el conjunto de cambios realizados arrojó un resultado positivo por valor de $\$ 280.815 .000$ pesos colombianos para el año 2010, que se llevan al patrimonio como resultado de ejercicios anteriores, como lo establece el proceso de implementación por primera vez.

En los resultados por la implementación de IFRS en la Cooperativa, se observan efectos financieros adversos, sobre todo por la aplicación de los estándares relativos a los instrumentos financieros, debido a que gran parte de su capital social no cumple la definición de patrimonio que allí se establece al no estar considerado en su capital mínimo irreductible. Ante la evidencia de que los aportes quedarán clasificados según lo indicado, es de esperar que los reguladores colombianos revisarán las normas aplicables al deterioro de valor en convergencia con lo enunciado en el Decreto Reglamentario 2784 de 2012.
En resumen, los principales efectos de carácter financiero se incluyen en la tabla 6 , que consigna variaciones bastantes fuertes en el cambio del patrimonio que disminuye en 49,76\% para el año 2010. Entretanto, el pasivo no corriente se incrementó casi en 350\%, dada la reclasificación de los aportes para este rubro y el pasivo total cerca de $38 \%$. Esta situación implica que la estructura financiera (enfoque stakeholders) para el año 2010 pase de una composición de pasivo $56,30 \%$ y patrimonio $43,70 \%$ con PCGA a otra bajo el modelo NIIF de pasivo $78,01 \%$ y patrimonio $21,99 \%$. Así mismo, hay un efecto importante para la propiedad, planta y equipo como producto del uso del método de costo atribuido para el año 2010 en la transición hacia NIIF para PYME y de la reclasificación del anticipo de propiedad, planta y equipo que aparecía bajo el concepto de cuentas por cobrar bajo PCGA.

\begin{tabular}{|c|c|c|c|c|c|c|}
\hline \multirow{2}{*}{\multicolumn{2}{|c|}{ Concepto }} & \multirow[b]{2}{*}{ Valor inicial } & \multirow[b]{2}{*}{ Valor final } & \multicolumn{2}{|c|}{ Variación } & \multirow{2}{*}{$\begin{array}{l}\text { Nivel de } \\
\text { impacto }\end{array}$} \\
\hline & & & & \multirow{2}{*}{$\begin{array}{l}\text { Absoluta } \\
280.815 .315\end{array}$} & $\begin{array}{c}\text { Relativa } \\
(\%)\end{array}$ & \\
\hline $\begin{array}{l}\text { Resultado implemen } \\
\text { a } 31 \text { de diciembre de }\end{array}$ & $\begin{array}{l}\text { ación NIIF } \\
2010\end{array}$ & & & & & Bajo \\
\hline Patrimonio & 2010 & $\$ 40.124 .145 .000$ & $\$ 20.158 .245 .315$ & $(\$ 19.965 .899 .685)$ & $-49,76$ & Alto \\
\hline Pasivo no corriente & 2010 & $\$ 5.684 .347 .000$ & $\$ 25.420 .484 .000$ & $\$ 19.736 .137 .000$ & 347,20 & Alto \\
\hline $\begin{array}{l}\text { Propiedad, planta y } \\
\text { equipo }\end{array}$ & 2010 & $\$ 1.807 .497 .000$ & $\$ 2.989 .129 .000$ & $\$ 1.181 .632 .000$ & 65,37 & Medio \\
\hline $\begin{array}{l}\text { Estructura } \\
\text { financiera (enfoque } \\
\text { agentes) } 2010\end{array}$ & Pasivo & $56,30 \%$ & $78,01 \%$ & $21,71 \%$ & 38,57 & Alto \\
\hline & Patrimonio & $43,70 \%$ & $21,99 \%$ & $-21,71 \%$ & $-49,69$ & \\
\hline
\end{tabular}

Tabla 6. Principales efectos financieros por la implementación de IFRS para PYME en la Cooperativa ${ }^{10}$ Fuente: elaboración propia

10 Para la calificación del nivel de impacto, se analizaron la variación relativa y su incidencia para el desempeño financiero de la Cooperativa. 
448 / VOL. 15 / NO. 38 / JULIO-DICIEMBRE 2014

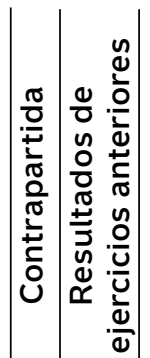

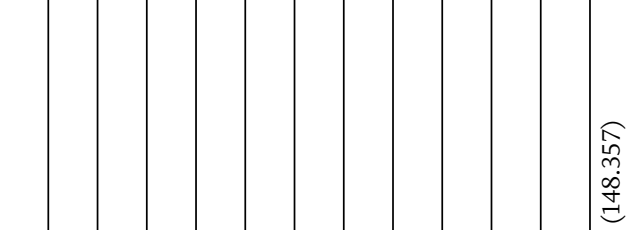

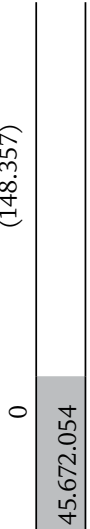

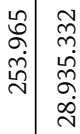

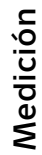

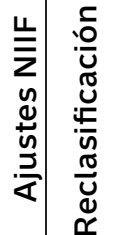

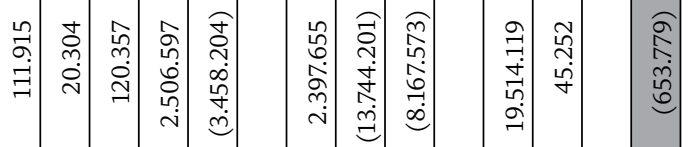

$\frac{\sqrt{\pi}}{\tilde{\pi}}$

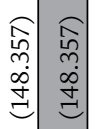

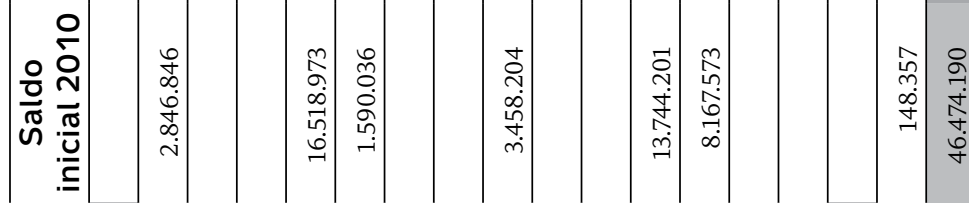

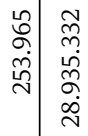

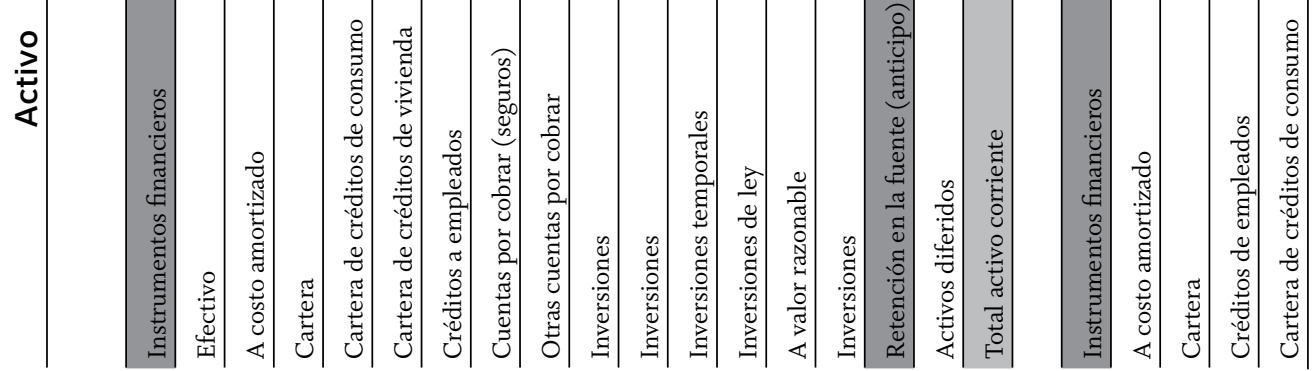


EFECTOS de LA NIIF PARA PYME / C. CAStAÑo, J. zAMARRA, J. CORREA / 449

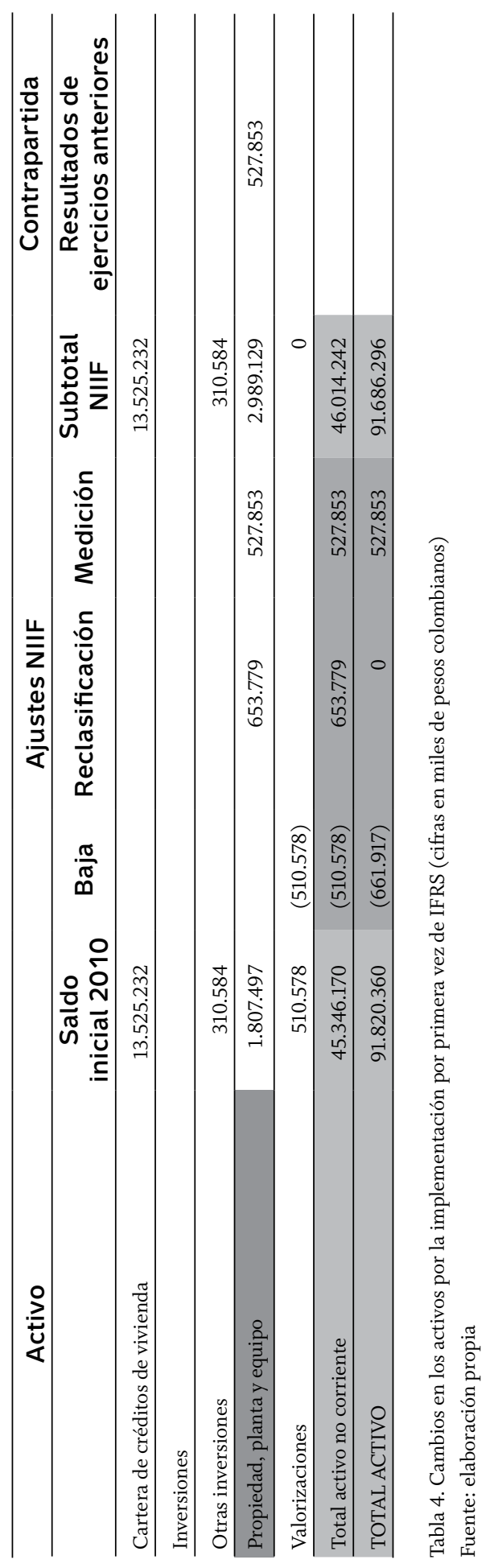


450 / VOL. 15 / NO. 38 / JULIO-DICIEMBRE 2014

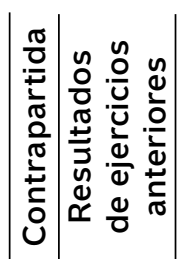

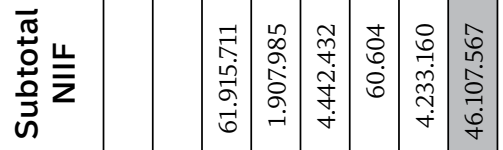

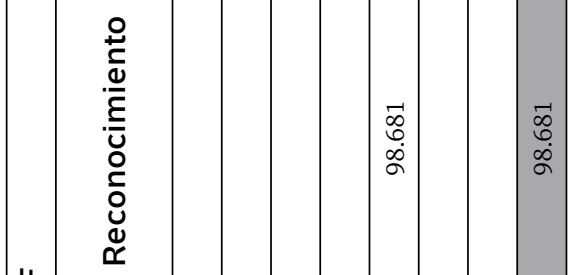

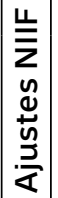

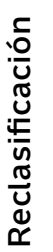

$\frac{\pi}{\pi}$

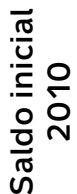

$\frac{9}{2}$

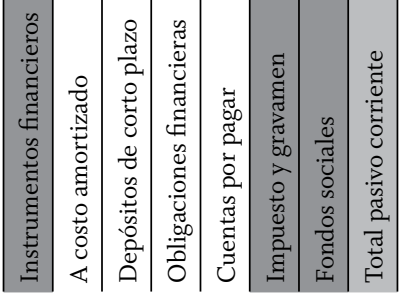

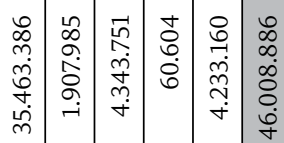

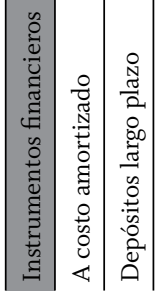

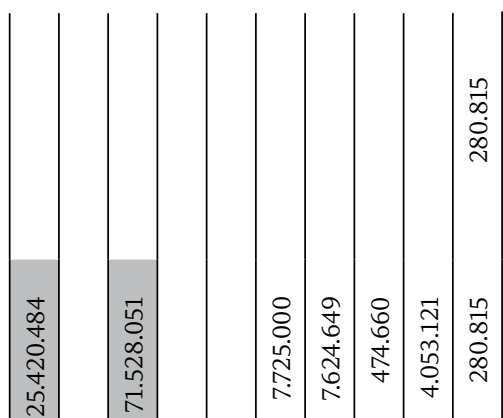

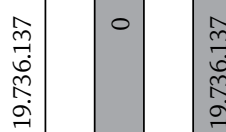

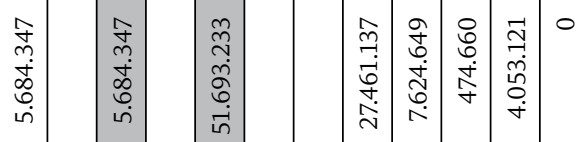

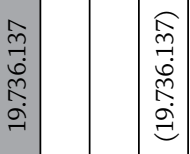

$\vec{\infty}$
0
$\infty$
$\infty$

$\circ$

宣

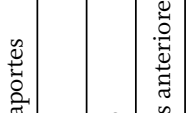

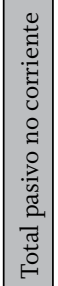

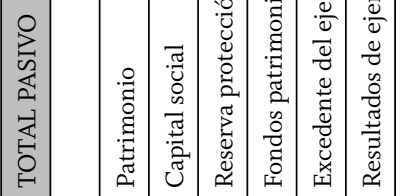


EFECTOS DE LA NIIF PARA PYME / C. CAStAÑo, J. ZAMARRA, J. CORREA / 451

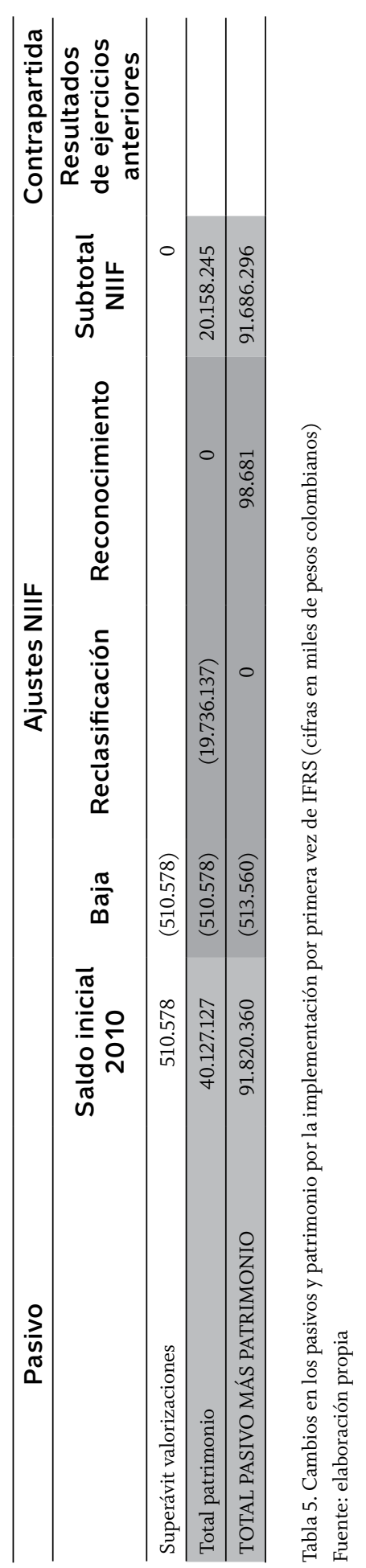


Además de lo anterior, se observa una fuerte variación en la estructura financiera de la empresa con un aumento del pasivo cercano al $40 \%$ y una disminución del patrimonio aproximada del 50\% frente a lo que se tenía con PCGA.

Los análisis realizados permiten saber cómo el cambio de modelo contable no solo se refleja en los rubros financieros, sino que genera un giro en la dinámica del negocio, por lo que se ratifica que toda la organización se ve afectada por la implementación del modelo NIIF.

\section{Consideraciones finales}

Mucho se podría plantear sobre los cambios contables y financieros que se van generando a medida que se asimila cada tema sobre los estándares internacionales de información financiera para PYME. No obstante, el debate que se suscita sobre el tema de clasificación del patrimonio de una entidad sin ánimo de lucro como la Cooperativa evaluada, hace pensar que el modelo fue diseñado en un contexto totalmente diferente a la lógica que implican los principios solidarios de este tipo de entidades en el país. No solo en Colombia se han pronunciado a este respecto pues autores como Javier Iturrioz-del Campo y Sonia Martín-López (2008), Sergio Marí-Vidal (2006) y Rafael Molina-Llopis (2007), Manuel Cubedo-Tortonda (2007) y Fernando Polo-Garrido (2007), en el caso español, manifiestan la improcedencia de la aplicación de estos estándares internacionales para el sector cooperativo, incluso analizando la interpretación particular para el patrimonio de las entidades cooperativas (CINIIF 2). Sumado a ello, el 23 de octubre de 2012, CONFECOOP realizó una presentación dirigida al CTCP en la que expuso los casos de Costa Rica y Alemania, países en los cuales se hacen exenciones o no aplicación de las NIIF para el sector cooperativo e hizo algunas propuestas para frenar estos efectos negativos que se esperan al tratar la temática de los instrumentos financieros, con su respectivo impacto en el patrimonio ya demostrado a lo largo del caso aquí analizado. Sin embargo, ante esta situación, es vital que los procesos de planeación de este tipo de entidades se fortalezcan para evitar al máximo los impactos negativos.

Los efectos financieros, que varían fuertemente según la preparación de cada entidad. Para el caso analizado, se obtuvieron efectos negativos por la implementación de IFRS para PYME, dado que disminuye significativamente el patrimonio de la entidad y aunque para el período evaluado no se observe un proceso de iliquidez, esta situación no sería sostenible en el tiempo, pues ante la ausencia de una adecuada planeación, los costos de operación se podrían incrementar ostensiblemente. Consecuentemente, se generarían impactos sociales negativos que redundarían en un deterioro del bienestar de los asociados y sus familias al contar la Cooperativa con menos excedentes para la labor social, de educación, apoyo en seguros, auxilios económicos, menores tasas de interés, limitaciones al consumo de crédito de los asociados y sus familias. Además, vale la pena recordar que esta situación es negativa para la Educación Superior Formal, pues esto implicaría un menor valor de la contribución que se establece hoy en la circular 4 de 2008 por un 
monto del 20\% de los excedentes dirigidos en especial a este concepto.

Otra alternativa podría ser en el caso de generar este cambio del capital social hacia pasivo sin costo; no obstante, el estándar internacional establece que se reconoce por el método del costo amortizado y deja un costo por interés que no tendría implicaciones desde el punto de vista del efectivo, pero sí en el excedente financiero configurando una doble partida tanto de ingreso como costo.

$\mathrm{Al}$ implementar las IFRS para PYME, es bastante importante revisar rubro por rubro los impactos que generan estas normas o estándares, lo cual se espera sea un ejercicio riguroso. De este modo, se inicia por el reconocimiento y no reconocimiento de activos, pasivos y patrimonio hasta llegar a su proceso de medición en la implementación por primera vez y los efectos que esto trae a futuro.

La gestión eficiente de los recursos depende en gran parte de la calidad de la información que se suministra; por ello, es vital la capacitación para los gerentes y administradores de las distintas entidades del país a fin de que conozcan las implicaciones de este tipo de implementaciones de nuevos modelos de contabilidad para sus organizaciones.

En el ámbito gerencial, los cambios que representa la implementación de las NIIF para PYME son diversos; en particular, los impactos en las áreas de la dirección administrativa y la dirección financiera son altos, pues hay cambios significativos que deben ser analizados y evaluados en detalle para que este proceso de adaptación no lleve a traumatismos en la gestión de la entidad.
Por otro lado, a fin de sintonizarse completamente con los estándares internacionales de información financiera, la Cooperativa debe iniciar un proceso de acoplamiento de sus sistemas de información para que puedan soportar estos cambios en la información financiera y para que se tenga la información de base para aplicar los procedimientos establecidos por los estándares internacionales de información financiera. Así mismo, el personal involucrado en estos procesos debe estar consciente de su rol en el suministro de información en esta cadena que se genera para llegar a los reportes bajo IFRS. También la forma en que se gestionan los recursos como los créditos, las tasas de interés y los costos de operación, entre otros, será fundamental a la hora de implementar las IFRS y tener un efecto positivo. Este trabajo constituye un primer insumo para la preparación a la adopción de los mencionados estándares.

Ante la ausencia de planeación y consenso, la continuidad de la Cooperativa se vería comprometida bajo el escenario propuesto de reconocerles a sus asociados el pago de intereses por los aportes. Aquí surge la alternativa de que los mismos asociados no cobren por estos depósitos un rendimiento y que la entidad reconozca tanto el ingreso como el costo en contrapartida. Otra alternativa es que durante los próximos años se capitalice la mayor cantidad posible de excedentes bajo la modalidad de capital institucional, con lo cual el patrimonio al momento de la implementación real de IFRS para PYME podría estar mucho más fortalecido. Además, existe la posibilidad de reformar los estatutos para que los asociados tengan un valor mayor de sus aportes como no retirable 
una vez que se renuncie o se desvincule de la Cooperativa; de este modo, un componente de los aportes actuales sería capital y otra parte sería pasivo.

\section{Referencias}

Cañibano-Calvo, Leandro \& Gisbert-Clemente, Ana (2007). El proceso de armonización contable internacional, la estrategia europea y la adaptación de la normativa contable en España. Contaduría Universidad de Antioquia, 51, 11-40. Disponible en: http://aprendeenlinea.udea.edu.co/revistas/ index.php/cont/article/view/2128/1738

Callao-Gastón, Susana; Ferrer-García, Cristina; Jarne-Jarne, José Ignacio \& Laínez-Gadea, José Antonio (2010). IFRS Adoption in Spain and the United Kingdom: Effects on Accounting Numbers and Relevance. Advances in International Accounting, 26, 304-313. Disponible en: http://www. viiaccountingworkshop.upct.es/papers/7ad0 3bba73cd60d90a40e099474c03d7.pdf

Cárdenas-Espinosa, Rubén Darío (2010). Las organizaciones solidarias en Colombia: una experiencia alternativa en la modernización del Estado. Observatorio de la Economía Latinoamericana, 130, online. Disponible en: http://www.eumed.net/cursecon/ecolat/ co/10/rdce.htm

Casinelli, Hernán Pablo (2012). Adopción por primera vez de las NIIF: análisis práctico de la NIIF 1. Buenos Aires: Osmar D. Buyatti. Colombia (1993). Decreto 624 de 1989, por el cual se expide el Estatuto Tributario de los impuestos administrados por la Dirección
General de Impuesto Nacionales. Diario Oficial, 38.756, 30 de marzo de 1989. Disponible en: http://www.alcaldiabogota. gov.co/sisjur/normas/Norma1.jsp?i=6533 Colombia (1993). Decreto reglamentario 2649 de 1993, por el cual se reglamenta la contabilidad en general y se expiden los principios o normas de contabilidad generalmente aceptados en Colombia. Diario Oficial, 41.156, 29 de diciembre de 1993. Disponible en: http:// www.alcaldiabogota.gov.co/sisjur/normas/ Norma1.jsp?i $=9863$

Colombia (2012). Decreto reglamentario 2706 de 2012, por el cual se reglamenta la Ley 1314 de 2009 sobre el marco técnico normativo de información financiera para las microempresas. Diario Oficial, 48.657, 28 de diciembre de 2012. Disponible en: http:// www.alcaldiabogota.gov.co/sisjur/normas/ Norma1.jsp?i $=51148$

Colombia (2012). Decreto reglamentario 2784 de 2012, por el cual se reglamenta la Ley 1314 de 2009 sobre el marco técnico normativo para los preparadores de información financiera que conforman el Grupo 1. Diario Oficial, 48.658, 29 de diciembre de 2012. Disponible en: http://www.supersociedades.gov.co/ asuntos-economicos-y-contables/procesosde-convergencia-niifs/leyes-y-decretos/ Documents/Anexos_2012_decreto_2784. pdf

Colombia (2013). Decreto reglamentario $1851 \mathrm{de}$ 2013, por el cual se reglamenta la Ley 1314 de 2009 sobre el marco técnico normativo para los preparadores de información financiera que se clasifican en el literal a) del parágrafo del artículo 10 del Decreto 2784 de 2012 y 
que hacen parte del Grupo 1. Diario Oficial, 48.897, 29 de agosto de 2013. Disponible en: http://www.alcaldiabogota.gov.co/sisjur/ normas/Norma1.jsp?i $=54378 \# 0$

Colombia (2013). Decreto reglamentario 3019 de 2013, por el cual se modifica el Marco Técnico Normativo de Información Financiera para las Microempresas, anexo al Decreto 2706 de 2012. Diario Oficial, 49.016, 27 de diciembre de 2013. Disponible en: http:// www.supersociedades.gov.co/asuntoseconomicos-y-contables/procesos-deconvergencia-niifs/leyes-y-decretos/ Paginas/default.aspx

Colombia (2013). Decreto reglamentario 3022 de 2013, por el cual se reglamenta la Ley 1314 de 2009 sobre el marco técnico normativo de información financiera que conforman el Grupo 2. Diario Oficial, 49.016, 27 de diciembre de 2013. Disponible en: http:// www.icbf.gov.co/cargues/avance/docs/ decreto_3022_2013.htm

Colombia (2013). Decreto reglamentario 3024 de 2013, por el cual se modifica el Decreto 2784 de 2012 y se dictan otras disposiciones. Diario Oficial, 49.016, 27 de diciembre de 2013. Disponible en: http://www.alcaldiabogota. gov.co/sisjur/normas/Norma1.jsp?i=56211 Colombia (1998). Ley 454 de 1998, por la cual se determina el marco conceptual que regula la economía solidaria, se transforma el Departamento Administrativo Nacional de Cooperativas en el Departamento Administrativo Nacional de la Economía Solidaria, se crea la Superintendencia de la Economía Solidaria, se crea el Fondo de Garantías para las Cooperativas Financieras y de Ahorro y Crédito, se dictan normas sobre la actividad financiera de las entidades de naturaleza cooperativa y se expiden otras disposiciones. Diario Oficial, 43.357, 6 de agosto de 1998. Disponible en: http://www. secretariasenado.gov.co/senado/basedoc/ ley_0454_1998.html

Colombia (2009). Ley 1314 de 2009, por la cual se regulan los principios y normas de contabilidad e información financiera y de aseguramiento de información aceptados en Colombia, se señalan las autoridades competentes, el procedimiento para su expedición y se determinan las entidades responsables de vigilar su cumplimiento. Diario Oficial, 47.409, 13 de julio de 2009. Disponible en: http://www. secretariasenado.gov.co/senado/basedoc/ ley_1314_2009.html

Comité de expertos del sector cooperativo (2012). Comentarios a la propuesta de normas de contabilidad e información financiera para la convergencia hacia estándares internacionales. Disponible en: http://www.ctcp.gov.co/sites/default/ files/Aplicación\%20NIIF\%20Sector\%20 Cooperativo $\% 20$ Colombiano $\% 20$ Documento\%202_0.pdf

Confederación de Cooperativas de Colombia, CONFECOOP (2012a). Economía solidaria 2006-2011. Disponible en: http://www. portalcooperativo.coop/index.php/ estadisticas

Confederación de Cooperativas de Colombia, CONFECOOP (2012b). Tratamiento de los aportes sociales de los asociados a las cooperativas. Presentación NIIF submesa 
regulación, sector cooperativo. 23 de octubre de 2012.

Consejo Técnico de la Contaduría Pública, CTCP (5 de diciembre de 2012).

Direccionamiento estratégico: del proceso de convergencia de las normas de contabilidad e información financiera y de aseguramiento de la información, con estándares internacionales. Bogotá: Consejo Técnico de la Contaduría Pública, CTCP. Disponible en: https://www.kpmg.com/CO/es/ IssuesAndInsights/ArticlesPublications/ Documents/DIR-ESTR-2012\%20CTCP.pdf Cubedo-Tortonda, Manuel (2007). El régimen económico de las sociedades cooperativas: situación actual y apuntes para una reforma. Ciriec-España, Revista de Economía Pública, Social y Cooperativa, 58, 161-187. Disponible en: http://www.redalyc.org/ articulo.oa?id=17405807

Deloitte (2008). Globalización contable: guía para la adopción de los IFRS. Bogotá: Editorial Planeta.

La Cooperativa (2012). Balance gestión integral 2011. Medellín: La Cooperativa.

International Accounting Standards Board, IASB (2009). IFRS for SMEs. Versión en español disponible en: https://www.deloitte.com/ view/es_co/co/biblioteca-tecnica/recursosifrs/ifrs-para-pymes/index.htm

International Accounting Standards Board, IASB (2010). Marco conceptual de IFRS. International Accounting Standards Board, IASB (2011). International Financial Reporting Standards. IFRS 9, IAS 39, IAS 16, IAS 1. Iturrioz-del Campo, Javier \& Martín-López, Sonia (2008). Perspectiva económico financiera de las implicaciones del nuevo plan general contable en las sociedades. En Julio Pindado-García \& Gregory Payne (coords.). Estableciendo puentes en una economía global, vol. 1, 68. Congreso Nacional de la Asociación Europea de Dirección y Economía de empresa. Disponible en: http://dialnet.unirioja.es/ servlet/articulo?codigo $=2723525$ Jiménez-Jaimes, Néstor Alberto (2011). Conversión del balance de apertura hacia las NIIF: de la teoría a la práctica. Revista Internacional Legis de Contabilidady Auditoría, 45, 41-171.

Lima-Fosado, Rafael (2007). Información financiera para pymes. Revista del Centro de Investigación de la Universidad de la Salle, 27 (7), 67-75. Disponible en: http://www. redalyc.org/articulo.oa?id=34202705 Mantilla, Samuel Alberto (2011). Estándares/ Normas Internacionales de Información Financiera (IFRS/NIIF) 2a ed. Bogotá: ECOE Ediciones.

Marí-Vidal, Sergio (2006). Efectos de la aplicación de la CNIIF 2 en las cooperativas. Un estudio empírico en dos cooperativas citrícolas de la comunidad valenciana a través del análisis económicofinanciero. Revesco, Revista de Estudios Cooperativos, 89, 84-107. Disponible en: http://revistas.ucm.es/index.php/REVE/ article/view/REVE0606230084A/19101 Molina-Llopis, Rafael (2007). La reforma de la legislación mercantil en materia contable. Una breve referencia a su incidencia en las cooperativas y sociedades laborales. CIRIECEspaña, Revista de Economía Pública, Social y 
Cooperativa, 58 109-129. Disponible en: http:// www.redalyc.org/pdf/174/17405805.pdf

Pérez-Estébanez, Raquel; Urquía-Grande, Elena \& Muñoz-Colomina, Clara Inés (2009). ¿Las pymes españolas tienen interés por las NIIF? Partida Doble, 215, 20-26.

Polo-Garrido, Fernando (2007). Impactos de las normas internacionales de información financiera en el régimen económico de las sociedades de las sociedades cooperativas. CIRIEC-España, Revista de Economía Pública, Social y Cooperativa, 58, 83-108. Disponible en: http://www.redalyc.org/ pdf/174/17405804.pdf

Silva-Palavecinos, Berta \& Garrido-Suazo, Claudio (2006). La convergencia a las normas internacionales de información financiera en Chile. Capic Review, 4, 9-19. Disponible en: http://www.capic.cl/capic/ media/ART1SilvaGarrido.pdf

Superintendencia de la Economía Solidaria, Supersolidaria (2013a). Circular externa 1, proceso de aplicación del marco teórico normativo para los preparadores de información financiera para el grupo 1 y 3. Disponible en: http://www.supersolidaria. gov.co/es/normativa/circulares-externas Superintendencia de la Economía Solidaria, Supersolidaria (2013b). Supersolidaria presenta resultados de la gestión. Disponible en: http://www.supersolidaria.gov.co/ noticia.php?n=296

Superintendencia de la Economía Solidaria, Supersolidaria (2013c). Circular externa 3, modificación de la circular básica contable y financiera 004 de 2008. Disponible en: http://www.supersolidaria.gov.co/es/ normativa/circulares-externas

Superintendencia de la Economía Solidaria, Supersolidaria (2010). Circular básica contable y financiera, modificación del capítulo XVI de la circular contable y financiera 004 de 2008. Disponible en: http://www.supersolidaria.gov.co/es/ normativa/circulares-externas

Torres-Agudelo, Fabiola \& Rodríguez-Castro, Braulio Adriano (2008). La maximización de los beneficios bajo los estándares de contabilidad financiera: una aproximación a las aplicaciones en la PYME. Cuadernos de Contabilidad, 4 (24), 73-130. Disponible en: http://www.javeriana.edu.co/fcea/ cuadernos_contab/vol9_n_24/vol9_24_4.pdf

Vásquez-Quevedo, Noemí; Carril-Márquez, Mariana Andrea \& Pascual-García, María (2013). Estado actual de Latinoamérica en relación a su proceso de adopción de las NIIF. Contabilidad \& Auditoría, Investigaciones en teoría contable, 19 (38), 55-104. Disponible en: http://www.econ. uba.ar/www/institutos/contable/archivos/ contabilidad_auditoria/38_REVISTA_ EN\%20LINEA_ISSN\%201852-446X.pdf Vásquez-Quevedo, Noemí (2013). Impacto de las IFRS en los reportes financieros de empresas listadas en la Bolsa Mexicana de Valores. Revista de Administración, Finanzas y Economía, 1 (6), 89-107.

Yáñez-Andrades, Verena; Pilar-Cortés, Fernando \& Inostrosa-Gonzáles, Claudio (2010). Impacto de las IFRS en la valoración de empresas: evidencia para una muestra de empresas chilenas cotizadas. 
Activos, 15, 135-162. Disponible en: http:// contaduria.usta.edu.co/images/documentos/ activos/15-6.pdf

Zapata, Gerardo \& Hernández-Arias, Aymara (2010). Reflexiones sobre la aplicación de las NIIF en las pymes venezolanas. Compendium, 13 (25), 23-41. Disponible en: http://www.redalyc.org/articulo. oa?id $=88019355003$

- Fecha de recepción: 30 de agosto de 2013

- Fecha de aceptación: 15 de marzo de 2014

- Disponible en línea: 01 de julio de 2014

\section{Para citar este artículo}

Castaño-Rios, Carlos Eduardo; Zamarra-Londoño, Julián Esteban \& Correa-García, Jaime Andrés (2014). Efectos financieros en una cooperativa colombiana por la implementación de estándares internacionales de información financiera para las pyme en su balance de apertura. Cuadernos de Contabilidad, 15 (38), 427-458.

doi: 10.11144/Javeriana.cc15-38.efcc 